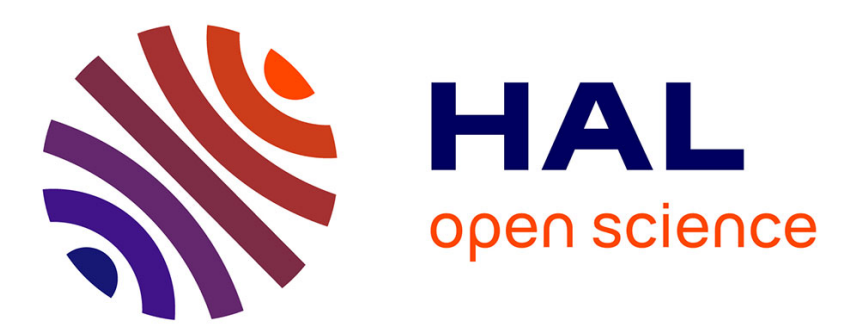

\title{
Reductive functionalization of CO2 with amines: an entry to formamide, formamidine and methylamine derivatives
}

Anis Tlili, Enguerrand Blondiaux, Xavier Frogneux, Thibault Cantat

\section{- To cite this version:}

Anis Tlili, Enguerrand Blondiaux, Xavier Frogneux, Thibault Cantat. Reductive functionalization of $\mathrm{CO} 2$ with amines: an entry to formamide, formamidine and methylamine derivatives. Green Chemistry, 2015, 17 (1), pp.157-168. 10.1039/C4GC01614A . hal-01187790

\author{
HAL Id: hal-01187790 \\ https://hal.science/hal-01187790
}

Submitted on 17 Nov 2015

HAL is a multi-disciplinary open access archive for the deposit and dissemination of scientific research documents, whether they are published or not. The documents may come from teaching and research institutions in France or abroad, or from public or private research centers.
L'archive ouverte pluridisciplinaire HAL, est destinée au dépôt et à la diffusion de documents scientifiques de niveau recherche, publiés ou non, émanant des établissements d'enseignement et de recherche français ou étrangers, des laboratoires publics ou privés. 


\title{
Green Chemistry
}

PERSPECTIVE

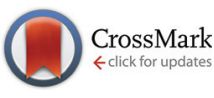

Cite this: Green Chem., 2015, 17, 157

\section{Reductive functionalization of $\mathrm{CO}_{2}$ with amines: an entry to formamide, formamidine and methylamine derivatives}

\author{
Anis Tlili, Enguerrand Blondiaux, Xavier Frogneux and Thibault Cantat*
}

Received 20th August 2014, Accepted 23rd October 2014

DOI: $10.1039 / c 4 g c 01614 a$

www.rsc.org/greenchem

\begin{abstract}
$\mathrm{CO}_{2}$ utilization for the production of $\mathrm{C}_{1}$-containing molecules is a desirable route to value-added chemicals. In this perspective, we summarize the recent results devoted to the formation of nitrogen compounds obtained by reductive functionalization of $\mathrm{CO}_{2}$ in the presence of amines. Using mild reductants, such as molecular hydrogen, hydrosilanes and hydroboranes, novel catalytic reactions have been designed in the last few years to facilitate the reductive functionalization of $\mathrm{CO}_{2}$ to formamide, formamidine and methylamine derivatives. While early efforts were devoted to the formylation of $\mathrm{N}-\mathrm{H}$ bonds, efficient organic and metal catalysts have been developed lately to promote the complete deoxygenation of $\mathrm{CO}_{2}$ to benzimidazoles, quinazolinones, formamidines and methylamines. Finally, the opportunities and challenges facing the practical use of $\mathrm{CO}_{2}$ in the production of nitrogen-containing molecules are discussed.
\end{abstract}

\section{Introduction}

While the $\mathrm{CO}_{2}$ concentration in the atmosphere has exceeded the symbolic 400 ppm level this year, the search for technologies to reduce $\mathrm{CO}_{2}$ emissions is becoming urgent. ${ }^{1}$ A myriad of solutions have been proposed and are currently explored, either at the research or technological stages. $\mathrm{CO}_{2}$ Capture and Storage (CCS) technologies have the potential to mitigate meaningful volumes of $\mathrm{CO}_{2}$ and a few demonstration plants are slowly emerging. ${ }^{2}$ It is foreseeable, however, that this technology will suffer from the lack of added-value able to compensate for the energetic and economic cost of $\mathrm{CO}_{2}$ capture and deposition and the monitoring of the storage sites. The 30 Gt- $\mathrm{CO}_{2}$ emitted annually primarily derives from the mineralization of carbon fossil resources, i.e. hydrocarbons, coal and gas. $^{3}$ In fact, utilization of these feedstocks in the fuel sector represents $80 \%$ of the world energy portfolio and their transformation in the chemical industry accounts for the production of $95 \%$ of organic chemical commodities. ${ }^{3}$ In this context, $\mathrm{CO}_{2}$ transformation into fuels and chemicals is a desirable alternative to $\mathrm{CO}_{2}$ storage for cutting the emissions of this greenhouse gas, while creating added value able to compensate for the costs of its capture.

CEA, IRAMIS, SIS2M, CNRS UMR 3299, 91191 Gif-sur-Yvette, France. E-mail: thibault.cantat@cea.fr; Fax: +33 16908 6640.http://iramis.cea.fr/Pisp/thibault.cantat/index.html
Yet, the chemical recycling of $\mathrm{CO}_{2}$ faces two energetic challenges. First, the thermodynamic stability of $\mathrm{CO}_{2}$ imposes an input of energy to convert $\mathrm{CO}_{2}$ into fuels and chemicals. The second challenge is kinetic in nature: catalysts are required to ensure that the activation barriers remain as low as possible along the chemical transformation pathways so that the overall carbon balance for $\mathrm{CO}_{2}$ utilization is not hampered by thermal loading needed to overcome high energy transition states. Obviously, these energetic considerations are associated with strong constraints on the resources utilized for $\mathrm{CO}_{2}$ conversion as the energy input must be carbon-free and rare or toxic metal catalysts must be avoided.

As a result of these limitations, only a handful of processes utilizing $\mathrm{CO}_{2}$ as a $\mathrm{C}_{1}$ building block have been industrialized to date, namely the Bosch-Meiser process for the production of urea from $\mathrm{CO}_{2}$ and ammonia, the Kolbe-Schmitt synthesis of salicylic acid (from $\mathrm{CO}_{2}$ and phenol) and the transformation of $\mathrm{CO}_{2}$ into carbonates. ${ }^{4}$ In total, they represent more than $70 \%$ of the total utilization of $\mathrm{CO}_{2}$ and less than $1 \%$ of the current anthropogenic $\mathrm{CO}_{2}$ emissions (Fig. 1). ${ }^{3}$ It is worth noting that, in these processes, $\mathrm{CO}_{2}$ is only functionalized: new $\mathrm{C}-\mathrm{O}$ and $\mathrm{C}-\mathrm{N}$ bonds are formed with no formal reduction of the $\mathrm{CO}_{2}$ carbon atom. In this context, a research field is expanding quickly to provide innovative transformations to produce organic ureas, urethanes, isocyanates and $\mathrm{N}$-heterocycles featuring a $\mathrm{C}^{\mathrm{IV}}$ center, by $\mathrm{CO}_{2}$ functionalization. ${ }^{5}$

In contrast, $\mathrm{CO}_{2}$ reduction to formic acid, methanol, methane or light alkanes is attracting increased attention because of the potential utilization of these molecules as fuels 


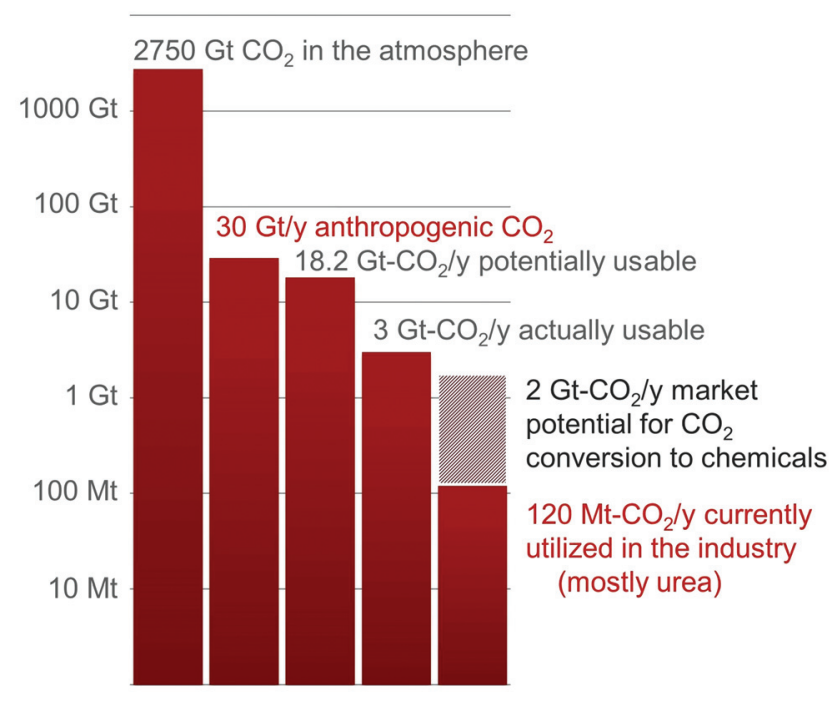

Fig. 1 Current and potential market volumes for the conversion of $\mathrm{CO}_{2}$ to chemicals.

or hydrogen carriers. ${ }^{2 \mathrm{a}, 6} \mathrm{CO}_{2}$ reduction to fuels has the capacity to reduce significantly $\mathrm{CO}_{2}$ emissions by recycling about $95 \%$ of the $30 \mathrm{Gt}-\mathrm{CO}_{2}$ released every year by human activities. ${ }^{3}$ Nonetheless, the low market value of these compounds is set by the petrochemical industry and their competitive production from $\mathrm{CO}_{2}$ remains an unsolved challenge. Indeed, these molecules are energy intensive and their production from $\mathrm{CO}_{2}$ requires a large amount of "carbon-free" hydrogen, whose cost exceeds natural gas reforming. ${ }^{7}$ Remarkably, a Mt per year pilot-plant is operated by Carbon Recycling International (CRI) that takes advantage of renewable geothermal energy in Iceland to produce methanol from $\mathrm{CO}_{2} \cdot{ }^{7,8}$

On the other hand, $\mathrm{CO}_{2}$ conversion to chemicals might offer niche applications in the short term, because the endproducts possess an added-value able to balance the cost of $\mathrm{CO}_{2}$ capture and transformation. In this regard, $\mathrm{CO}_{2}$ is an attractive carbon feedstock in synthesis, as it is non-toxic, costefficient, secured and well-distributed. It should be pointed out that this application will not reduce significantly our carbon footprint, as it scales to a maximum of $7 \%$ of the anthropogenic $\mathrm{CO}_{2}$ emissions and $11 \%$ of the $18.2 \mathrm{Gt}-\mathrm{CO}_{2}$ per year produced at point sources (Fig. 1). ${ }^{3}$ However, this field could offer viable technologies for the recycling of $\mathrm{CO}_{2}$ and increase at the same time our knowledge on $\mathrm{CO}_{2}$ reduction to foster emerging industrial applications. ${ }^{7}$ Notably, the scope of chemicals directly available from $\mathrm{CO}_{2}$ remains very narrow, compared to current available petrochemicals. Even at the laboratory scale, the majority of the basic organic functional groups, such as ketones, amides and esters, are presently unavailable from carbon dioxide. ${ }^{5}$ Indeed, these functionalities feature a carbon atom that is both functionalized and reduced. As a result of these limitations, considerable efforts have been devoted recently to promote the reductive functionalization of $\mathrm{CO}_{2}$ and widen the spectrum of chemicals accessible from $\mathrm{CO}_{2}$. For example, Willauer et al. have recently investigated the formation of light olefins from $\mathrm{CO}_{2} / \mathrm{H}_{2}$ over heterogeneous catalysts. ${ }^{6 \mathrm{n},}{ }^{9}$ The utilization of $\mathrm{CO}_{2}$ as a carboxylation reagent for the formation of $\mathrm{C}-\mathrm{C}$ bonds is also a hot topic which has been the subject of excellent reviews. ${ }^{10}$

Herein, we review the results obtained in $\mathrm{CO}_{2}$ conversion using amines as functionalizing reagents, in the presence of mild reductants having a redox potential close to the $\mathrm{CO}_{2} /$ $\mathrm{CH}_{3} \mathrm{OH}$ couple (e.g. $\mathrm{H}_{2}$, hydrosilanes and hydroboranes). Initiated in the 1970 s, this field has witnessed a rapid development over the past five years with the design of novel processes able to transform $\mathrm{CO}_{2}$ and amines into formamide, formamidine and methylamine derivatives.

\section{Formylation of $\mathrm{N}-\mathrm{H}$ bonds with $\mathrm{CO}_{2}$}

The formylation of amines with $\mathrm{CO}_{2}$ is an important transformation since the desired formamide products are versatile chemicals and key building blocks. Among them, $N, N$-dimethylformamide (DMF) is a widely utilized polar solvent as well as an important chemical reagent utilized in a multitude of applications in organic synthesis. ${ }^{11}$ It is produced industrially by the carbonylation of dimethylamine (DMA) in the presence of methanol. ${ }^{12}$ An alternative synthesis route based on the use of $\mathrm{CO}_{2}$ instead of the toxic carbon monoxide and starting with dimethylamine in the presence of a reductant has attracted several research groups for a long time. Thereby especially homogeneous or heterogeneous transition metal catalysts have been proven to have high potential. The most efficient and promising systems are overviewed thereafter.

The successive reduction of $\mathrm{CO}_{2}$ with hydrogen can afford formic acid, formaldehyde, methanol and methane. Although the formation of methanol from $\mathrm{CO}_{2} / \mathrm{H}_{2}$ is thermodynamically favourable, the first reduction of $\mathrm{CO}_{2}$ to formic acid is uphill. As such, the addition of a base is usually needed to facilitate $\mathrm{CO}_{2}$ reduction to a formate derivative. Using a secondary amine, such as DMA, as a base for the hydrogenation of $\mathrm{CO}_{2}$ led to the formation of the corresponding formamide by condensation of the amine to the formate and paved the way to the catalytic formylation of amines with $\mathrm{CO}_{2} / \mathrm{H}_{2}$ mixtures. The first catalytic examples reported in the literature were based on the use of the stable heterogeneous RANEY ${ }^{\circledR}$ Nickel as a catalyst in $1935 .{ }^{13}$ Some amines including secondary amines (piperidine, phenylethylamine) as well as primary amines ( $n$-amylamine) were carbonylated to their corresponding formamides under quite drastic reaction conditions (60 bar of $\mathrm{CO}_{2}$, up to 160 bar of $\mathrm{H}_{2}$ and temperatures up to $250{ }^{\circ} \mathrm{C}$ ) with low to moderate yields. The first homogeneous catalyst was reported by Haynes et al. in $1970 .{ }^{14}$ Several well-defined complexes were tested for the synthesis of DMF, the most active being (dppe) $)_{2} \mathrm{CoH},\left(\mathrm{PPh}_{3}\right)_{2}(\mathrm{CO}) \mathrm{IrCl}$ and $\left(\mathrm{PPh}_{3}\right)_{3} \mathrm{CuCl}$ (dppe: 1,2-bis(diphenylphosphino)ethane) with TONs (TurnOver Numbers) reaching 1000. The reactions were performed at $125{ }^{\circ} \mathrm{C}$, with an equimolar mixture of $\mathrm{H}_{2}$ and $\mathrm{CO}_{2}$, at a total pressure of 54 bar (Table 1, entries 1 and 2). It is noteworthy 
Table 1 List of catalysts for DMF synthesis

\begin{tabular}{|c|c|c|c|c|c|c|}
\hline Entry & Catalyst & $\begin{array}{l}\mathrm{CO}_{2} \\
\text { (bar) }\end{array}$ & $\begin{array}{l}\mathrm{H}_{2} \\
\text { (bar) }\end{array}$ & $T\left({ }^{\circ} \mathrm{C}\right)$ & TON & Ref. \\
\hline 1 & $\left(\mathrm{PPh}_{3}\right)_{3} \mathrm{CuCl}$ & 27 & 27 & 125 & 900 & 9 \\
\hline 2 & $\left(\mathrm{PPh}_{3}\right)_{2}(\mathrm{CO}) \operatorname{IrCl}$ & 27 & 27 & 125 & 1200 & 9 \\
\hline 3 & $\mathrm{PdCl}_{2}$ & 40 & 80 & 170 & 34 & 10 \\
\hline 4 & $\left(\left[\mathrm{Pt}_{2}(\mu-\mathrm{dppm})_{3}\right]\right)$ & 12 & 94 & 75 & 1460 & 12 \\
\hline 5 & $\mathrm{RuCl}_{2}\left[\mathrm{P}\left(\mathrm{CH}_{3}\right)_{3}\right]_{4}$ & 130 & 80 & 100 & 370000 & 14 \\
\hline 6 & $\mathrm{RuCl}_{2}(\mathrm{dppe})_{2}$ & 130 & 85 & 100 & 740000 & 16 \\
\hline 7 & {$[\mathrm{Mo}](\mathbf{1})$} & 25 & 35 & 110 & 115 & 19 \\
\hline $8^{a}$ & $\mathrm{Cu} / \mathrm{ZnO}$ & 60 & 60 & 140 & 70 & 20 \\
\hline 9 & $\mathrm{Fe}\left(\mathrm{BF}_{4}\right)_{2} \cdot 6 \mathrm{H}_{2} \mathrm{O} / \mathrm{PP}_{3}$ & 30 & 60 & 100 & 727 & $6 i$ \\
\hline 10 & $\mathrm{Co}\left(\mathrm{BF}_{4}\right)_{2} \cdot 6 \mathrm{H}_{2} \mathrm{O} / \mathrm{PP}_{3}$ & 30 & 60 & 100 & 1300 & 21 \\
\hline 11 & $\mathrm{Fe}\left(\mathrm{BF}_{4}\right)_{2} \cdot 6 \mathrm{H}_{2} \mathrm{O} / \mathrm{PPAr}_{3}$ & 30 & 70 & 100 & 5100 & 22 \\
\hline
\end{tabular}

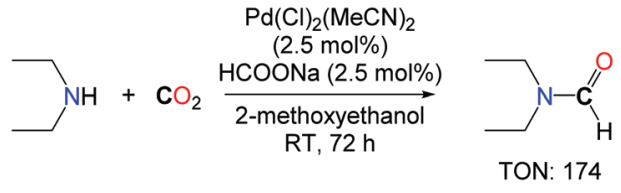

Scheme 1 Pd-promoted synthesis of diethylformamide.

that different secondary as well as primary amines could be formylated also under similar reaction conditions in the presence of $\mathrm{Rh}$ or Pt based catalysts.

Afterwards, Kudo et al. demonstrated that simple $\mathrm{PdCl}_{2}$ salt is an effective catalyst, with a catalyst loading of about $3 \mathrm{~mol} \%$, for the synthesis of DMF. ${ }^{15}$ The reactions were performed in the presence of 40 bar of $\mathrm{CO}_{2}, 80$ bar of $\mathrm{H}_{2}$ and potassium bicarbonate as the base. The best result was obtained when the reaction mixture was heated at $170{ }^{\circ} \mathrm{C}$ (Table 1 , entry 3 ).

Inspired by the system of Kudo et al. Morimoto et al. developed a new palladium based catalyst for the synthesis of diethylformamide. $^{16}$ An optimized ratio of sodium formate and 2-methoxyethanol $\left(0.05 \mathrm{mmol} \mathrm{mL}^{-1}\right)$ in the presence of a catalytic amount of $\mathrm{PdCl}_{2}(\mathrm{MeCN})_{2}(2.5 \mathrm{~mol} \%)$ under an atmospheric pressure of $\mathrm{CO}_{2}$ were sufficient to obtain diethylformamide in good yields, without the need for hydrogen (Scheme 1). It is unclear however whether $\mathrm{CO}_{2}$ is the source of the formyl group in this transformation, as the reaction was undertaken in the presence of a formate reagent which can either act as a formyl donor or a reductant for $\mathrm{CO}_{2}$. Interestingly, the authors demonstrated that tetraethylurea could also be obtained with very high activity and selectivity in the presence of a well-defined ratio of $\mathrm{PPh}_{3} / \mathrm{MeCN} / \mathrm{CCl}_{4}$, in the absence of any reductant.

A series of transition metals have also been tested by the group of Vaska. ${ }^{17}$ The most active catalyst for the synthesis of DMF starting from DMA and carbon dioxide (10-12 bar) in the presence of molecular hydrogen (67-94 bar) turned out to be a

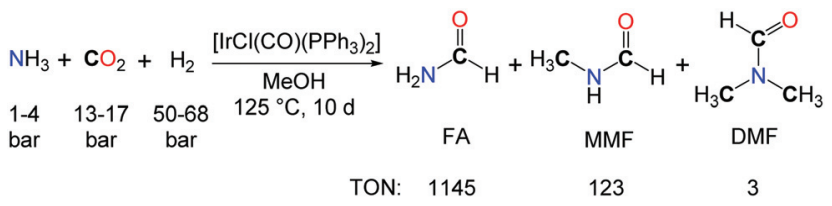

Scheme 2 Formylation of ammonia promoted by $\left[\mathrm{IrCl}(\mathrm{CO})\left(\mathrm{PPh}_{3}\right)_{2}\right]$.

platinum based catalyst $\left(\left[\mathrm{Pt}_{2}(\mu-\mathrm{dppm})_{3}\right]\right)$ (dppm: bis(diphenylphosphino)methane), working in toluene at $75{ }^{\circ} \mathrm{C}$ (Table 1 , entry 4). Importantly, the authors demonstrated that the synthesis of DMF could be achieved under very mild reaction conditions and 1 bar of each of the three gas reactants was successfully transformed at room temperature. Moreover, they demonstrated that in the presence of $\left.\left[\mathrm{Pt}_{2}(\mu-\mathrm{dppm})_{3}\right]\right)$ the formation of DMF is readily reversible by heating DMF at $150{ }^{\circ} \mathrm{C}$ under low pressure of $\mathrm{H}_{2}$ ( 1 bar).

The use of $\mathrm{NH}_{3}$ as a reactive substrate presents a further challenge as three $\mathrm{N}-\mathrm{H}$ bonds are potentially active in the formylation with $\mathrm{CO}_{2}$ and $\mathrm{H}_{2}$. The iridium complex $[\operatorname{IrCl}(\mathrm{CO})-$ $\left.\left(\mathrm{PPh}_{3}\right)_{2}\right]$ proved to be an effective catalyst for the synthesis of $N$-formylamine (FA) from $\mathrm{NH}_{3}, \mathrm{CO}_{2}$ and $\mathrm{H}_{2}$, in toluene or methanol solutions (Scheme 2). ${ }^{18}$ A TON of 1145 could be reached after 10 days. Yet, the source of the methyl groups in the methylated by-products (MMF: monomethylformamide, and DMF) was not established undoubtedly and could either originate from the hydrogenation of $\mathrm{CO}_{2}$ or the $\mathrm{MeOH}$ solvent.

An elegant procedure has been developed by Noyori in 1994 for the synthesis of DMF with TONs up to 370000 and with overall rates up to $10000 \mathrm{~h}^{-1}$. $^{19}$ The key of success of this system is the use of a well-defined homogeneous ruthenium catalyst, namely $\left(\mathrm{RuCl}_{2}\left[\mathrm{P}\left(\mathrm{CH}_{3}\right)_{3}\right]_{4}\right)$, with 80 bar $\mathrm{H}_{2}$, in supercritical $\mathrm{CO}_{2}\left(\mathrm{scCO}_{2}, 130\right.$ bar). $\mathrm{scCO}_{2}$ acts both as the reaction medium and the reactant and increases the solubility of the organic and gaseous reactants. It is noteworthy that the same results were obtained when the reactions were carried out with dimethylamine or the liquid dimethylammonium dimethylcarbamate as the source of DMA (Table 1, entry 5). The authors proposed that the formation of DMF proceeds via two steps. First, the ruthenium catalyst facilitates the hydrogenation of $\mathrm{CO}_{2}$ and the amine stabilizes the corresponding ammonium formate salt (Scheme 3, eqn (1)). In the second step, the catalyst promotes the condensation of the amine to the formate, to yield DMF (Scheme 3, eqn (2)). The same group demonstrated later on that the developed catalytic system could also be extended to the use of diethylamine and di- $n$-propylamine

$$
\begin{aligned}
& \mathrm{CO}_{2}+\mathrm{H}_{2} \frac{\text { cat.: } \mathrm{RuCl}_{2}\left(\mathrm{P}\left(\mathrm{CH}_{3}\right)_{3}\right)}{+\mathrm{Me}_{2} \mathrm{NH}}\left[\mathrm{Me}_{2} \mathrm{NH}_{2}\right]\left[\mathrm{HCO}_{2}\right] \text { (1) } \\
& {\left[\mathrm{Me}_{2} \mathrm{NH}_{2}\right]\left[\mathrm{HCO}_{2}\right] \frac{\text { cat.: } \mathrm{RuCl}_{2}\left(\mathrm{P}\left(\mathrm{CH}_{3}\right)_{3}\right)}{-\mathrm{H}_{2} \mathrm{O}}>^{\mathrm{N}-\mathrm{C}_{\mathrm{H}}} \mathrm{O}}
\end{aligned}
$$

Scheme 3 Ru-catalyzed synthesis of DMF from DMA, using $\mathrm{scCO}_{2}$ and $\mathrm{H}_{2}$. 
leading to the corresponding amides, albeit with a lower activity (TONs of 820 and 260, respectively). ${ }^{20}$ Moreover, when bulky dialkylamines were employed, only the corresponding ammonium formate salts were formed. It is likely that the condensation step is controlled both by the steric hindrance of the amine reagent and the solubility of the formate salt.

Inspired by the discovery of the group of Noyori, the group of Baiker reported a more efficient protocol for DMF synthesis. $^{21}$ A series of ruthenium complexes of the formula $\left[\mathrm{RuCl}_{2} \mathrm{~L}_{2}\right]$ have been prepared (L: dppm, dppe or dppp (1,3-bis(diphenylphosphino)propane)). The best catalyst system turned out to be $\left[\mathrm{RuCl}_{2}(\mathrm{dppe})_{2}\right]$ with very high TOFs (TurnOver Frequencies), up to $360000 \mathrm{~h}^{-1}$ (Table 1, entry 6). The experiments were performed at $100{ }^{\circ} \mathrm{C}$ in the presence of $130 \mathrm{bar}$ of $\mathrm{CO}_{2}$ and 85 bar of $\mathrm{H}_{2}$. Under these conditions, $530 \mathrm{~kg}$ of DMF could be produced within 2 hours. In continuity with this promising result, the group of Baiker focused on the immobilisation of ruthenium/phosphorus catalysts. ${ }^{22}$ The synthesis of mesoporous ruthenium silica hydride aerogel has been achieved using the sol-gel process. The obtained materials showed high catalytic activities in DMF synthesis, leading to turnover frequencies up to $18400 \mathrm{~h}^{-1}$.

After this work, the group of Tumas and Baker proposed a new alternative based on a biphasic system. ${ }^{23}$ The association of $\mathrm{ScCO}_{2}$ with 1-butyl-3-methylimidazolium hexafluorophosphate as the ionic liquid allowed for the hydrogenation of $\mathrm{CO}_{2}$ and the trapping of the formate ion by amines, catalyzed by $\mathrm{RuCl}_{2}$ (dppe) $)_{2}$, to yield the corresponding formamides under 55 bar of $\mathrm{H}_{2}$ and 221 bar of $\mathrm{scCO}_{2}$ at $80{ }^{\circ} \mathrm{C}$. Excellent selectivity has been observed with di- $n$-propylamine reaching a TON of 110.

In 2001, the group of Ito reported the application of a new class of molybdenum-based catalysts in DMF synthesis (Table 1, entry 7). ${ }^{24}$ Even though the catalytic productivity of this well-defined molybdenum-silyl/phosphorus catalyst with a TON of 115 (under $\mathrm{CO}_{2} / \mathrm{H}_{2}: 25 / 35$ bar) is lower than those of other noble metals reported, the introduction of a noble metal-free system is highly desirable for such transformations. It is worth noting here that the molybdenum complex $\mathbf{1}$, depicted in Scheme 4, reacts under 17 bar of $\mathrm{CO}_{2}$ at room temperature yielding the formate complex 2 . The insertion of $\mathrm{CO}_{2}$ into the Mo-H bond turned out to be reversible and 2 decarboxylates at $60{ }^{\circ} \mathrm{C}$ in benzene. Furthermore, 2 proved to be

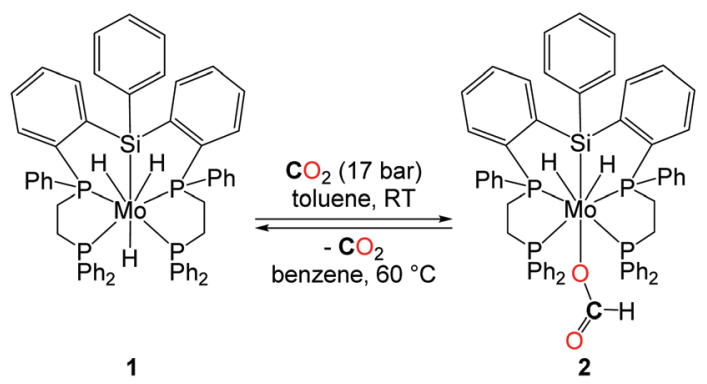

Scheme 4 Reversible insertion of $\mathrm{CO}_{2}$ in the $\mathrm{Mo}-\mathrm{H}$ bond of complex 1. active in the catalytic formation of DMF, suggesting that it could be a potential intermediate in the catalytic reaction pathway.

More recently, the group of Han disclosed a novel heterogeneous noble metal-free system. ${ }^{25}$ A mixture of $\mathrm{Cu}-\mathrm{ZnO}(3: 2)$ allows for the synthesis of DMF starting from dimethylammonium dimethylcarbamate with a very good yield of $97 \%$ (Table 1 , entry 8). The reactions were undertaken at $140{ }^{\circ} \mathrm{C}$ for $6 \mathrm{~h}$ under 120 bar of an equimolar mixture of $\mathrm{CO}_{2} / \mathrm{H} 2$.

Exploring the hydrogenation of $\mathrm{CO}_{2}$ with noble metal-free catalysts, the group of Beller, Laurenczy and co-workers described an efficient iron-based system. ${ }^{6 i}$ The active iron catalyst is generated in-situ from $\mathrm{Fe}\left(\mathrm{BF}_{4}\right)_{2} \cdot 6 \mathrm{H}_{2} \mathrm{O}$ and $\mathrm{PP}_{3}$ (tris[2-(diphenylphosphino)ethyl]phosphine) as a ligand. DMF was obtained in a very good yield (75\%) with a TON of 727 , after $20 \mathrm{~h}$ at $100{ }^{\circ} \mathrm{C}$, in the presence of 60 bar of molecular hydrogen and 30 bar of $\mathrm{CO}_{2}$ (Table 1, entry 9). Following this work, a novel cobalt catalyst $\left(\mathrm{Co}\left(\mathrm{BF}_{4}\right)_{2} \cdot 6 \mathrm{H}_{2} \mathrm{O} / \mathrm{PP}_{3}\right)$ was shown to exhibit an improved catalytic activity with a TON of 1308 for the production of DMF, using similar conditions (Table 1, entry 10). ${ }^{26}$ In continuity, they presented later on a more efficient iron-based catalyst, with a new tetradentate ligand $\left(\mathrm{PPAr}_{3}\right.$ : tris(2-(diphenylphosphino)phenyl)phosphine) able to promote successfully the hydrogenation of $\mathrm{CO}_{2}$ with $\mathrm{H}_{2}$ (Table 1, entry 11). DMF as well as diethylformamide could be obtained with good to moderate yields and with TONs respectively of 5104 and $2114 .^{27}$

In parallel to the search for highly active catalysts in the formylation of amines with $\mathrm{CO}_{2} / \mathrm{H}_{2}$, efforts were devoted to enlarging the scope of active amines in this transformation. In this respect, Süss-Fink et al. showed, in 1989, that the ruthenium clusters, e.g. $\mathrm{Ru}_{3}(\mathrm{CO})_{12},\left[\mathrm{HRu}_{3}(\mathrm{CO})_{11}\right]^{-}$and $\left[\mathrm{H}_{3} \mathrm{Ru}_{4}(\mathrm{CO})_{12}\right]^{-}$ (0.7 mol\%), were active under 60 bar of $\mathrm{CO}_{2}$ and 60 bar of $\mathrm{H}_{2}$ in $\mathrm{THF}$ at $140{ }^{\circ} \mathrm{C}$ to convert piperidine, 3-methylpiperidine, pyrrolidine, heptamethylene imine, morpholine and piperazine to their formamides (Scheme 5, I). ${ }^{28}$ Even though good selectivities as well as good yields could be obtained, lower TONs (down to 43) of the catalyst were observed. With a similar scope of amines, increased activity was noticed with $\left[\mathrm{RuCl}_{2}(\mathrm{dppe})_{2}\right]$, in the presence of supercritical $\mathrm{CO}_{2}$, with TONs ranging from 850 to 210000 , depending on the substrate and reaction conditions. ${ }^{29}$

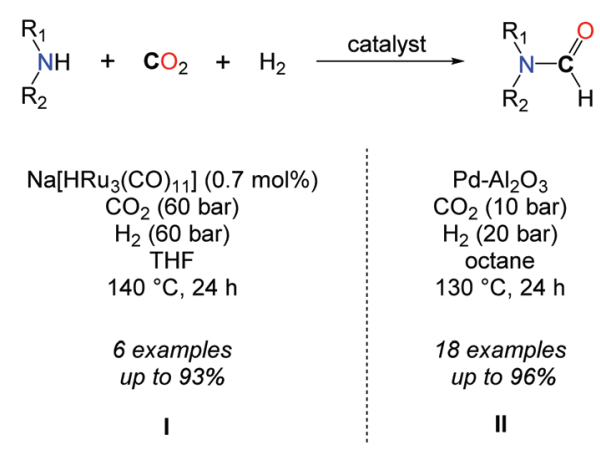

Scheme 5 Catalyzed formylation of amines using $\mathrm{CO}_{2}$ and $\mathrm{H}_{2}$. 


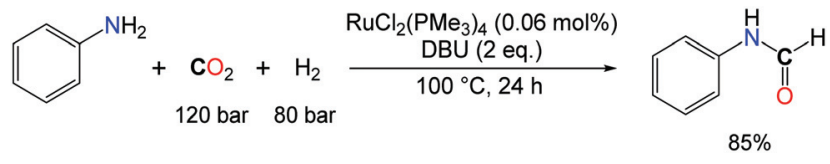

Scheme 6 Ru-promoted synthesis of formanilide from aniline.

The low basicity of aromatic amines significantly hampers the rates for the hydrogenation of $\mathrm{CO}_{2}$ and, in turn, the formylation of anilines with $\mathrm{CO}_{2}$ and $\mathrm{H}_{2}$ was found problematic. Interestingly, this limitation was circumvented by the group of Jessop with the use of extra bases. ${ }^{30}$ Indeed, conversion of $\mathrm{PhNH}_{2}$ to formanilide was achieved in $85 \%$ yield, using Noyori's system $\left(\mathrm{RuCl}_{2}\left(\mathrm{P}\left(\mathrm{CH}_{3}\right)_{3}\right)_{4}\right)$ at $100{ }^{\circ} \mathrm{C}$ for $10 \mathrm{~h}$, in the presence of 2 molar equivalents of DBU (1,8-diazabicyclo[5.4.0] undec-7-ene) as the additional base (Scheme 6).

To the best of our knowledge, only a heterogeneous palladium based catalyst, recently developed by the group of Shi, allows for the formylation of both aromatic and aliphatic secondary amines using $\mathrm{CO}_{2}$ in conjunction with $\mathrm{H}_{2}$ at quite low pressures $\left(\mathrm{CO}_{2} / \mathrm{H}_{2}: 10 / 20\right.$ bar) (Scheme 5 , II). ${ }^{31}$ A key feature of this system is the design of discrete palladium species supported on aluminium oxide. A variety of secondary aliphatic amines were converted into their corresponding formamide derivatives in very good to excellent yields. The authors demonstrated that the system is reusable and consistently good yields could be obtained after three runs. Nevertheless, it is not general since anilines and primary amines were very poorly converted to the desired products under the reaction conditions.

The search for alternative reductants able to promote the formylation of $\mathrm{N}-\mathrm{H}$ bonds with $\mathrm{CO}_{2}$ was motivated by the narrow scope encountered with $\mathrm{H}_{2}$. In this respect, the group of Tanaka proposed a novel approach for the synthesis of DMF based on the use of the discrete ruthenium complex $\left(\left[\mathrm{Ru}(\mathrm{bpy})_{2}(\mathrm{CO})_{2}\right]^{2+}\right)$ via the electrochemical reaction of $\mathrm{CO}_{2}$ with a mixture of dimethylamine and dimethylamine hydrochloride $\left(\mathrm{Me}_{2} \mathrm{NH} \cdot \mathrm{HCl}\right)$ with an efficiency of $21 \%$ with respect to DMF (Scheme 7). ${ }^{32}$

The key of success of this system is the reactivity of DMA with the ruthenium carbonyl complex that leads to the formation of a carbamoyl complex ([Ru(bpy $\left.\left.)_{2}(\mathrm{CO}) \mathrm{C}(\mathrm{O}) \mathrm{NMe}_{2}\right]^{+}\right)$, which undergoes a two electron reduction to yield DMF.

The development of more general methodologies is of high interest to establish the synthetic utility of $\mathrm{CO}_{2}$ as a $\mathrm{C}_{1}$ building block in the formylation of amines. Hydrosilanes $\left(\mathrm{R}_{3} \mathrm{Si}-\mathrm{H}\right)$ and hydroboranes $\left(\mathrm{R}_{2} \mathrm{~B}-\mathrm{H}\right)$ are excellent candidates for the reduction of $\mathrm{CO}_{2}$ because the slightly polar and weaker $\mathrm{Si}-\mathrm{H}$ and $\mathrm{B}-\mathrm{H}$ bonds (bond dissociation energy (BDE) $92 \mathrm{kcal} \mathrm{mol}^{-1}$
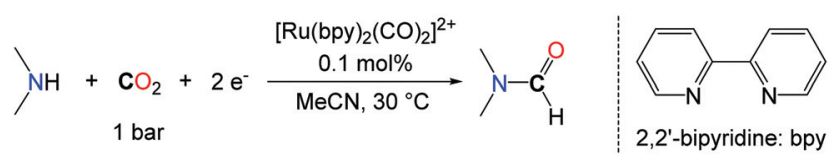

Scheme 7 Electrochemical synthesis of DMF.

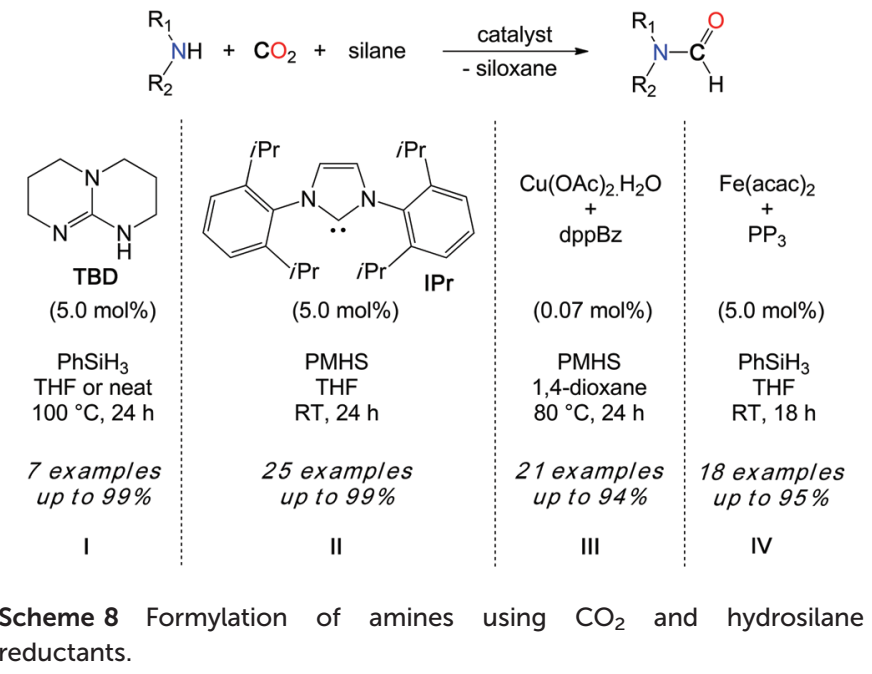

in $\mathrm{SiH}_{4}$ and $99 \mathrm{kcal} \mathrm{mol}^{-1}$ in $\mathrm{BH}_{3}$ ) are easier to activate than the strong non-polar $\mathrm{H}-\mathrm{H}$ bond (BDE $104 \mathrm{kcal} \mathrm{mol}^{-1}$ ). These reductants could in principle enlarge the spectrum of active substrates. In this context, in 2011, our group reported a novel catalytic reaction to promote the formylation of $\mathrm{N}-\mathrm{H}$ bonds, using $\mathrm{CO}_{2}$ as a carbon source and hydrosilanes as reductants. ${ }^{33}$

Interestingly, the kinetic advantage associated with the use of a hydrosilane reductant allows for the use of a metal-free system in the reduction of $\mathrm{CO}_{2}$. In fact, TBD (1,5,7-triazabicyclo[7.4.0]dec-5-ene) (5.0 mol\%) is able to convert secondary amines with good to excellent yields when the reactions are undertaken in $\mathrm{THF}$ at $100{ }^{\circ} \mathrm{C}$, with $\mathrm{PhSiH}_{3}$ (Scheme 8, I). Notably, the increased polarity of the solvent has a positive influence on the rate of the reaction and the best results were obtained in the absence of the solvent, where the polarity of the medium is augmented by the formation of the formamide product. While DMF was obtained in $80 \%$ yield from the carbamate $\left[\mathrm{Me}_{2} \mathrm{NCO}_{2}\right]\left[\mathrm{H}_{2} \mathrm{NMe}_{2}\right]$, the catalyst also enables the formylation of morpholine and diethylamine. Yet, primary amines such as $n$-hexylamine proved to be less reactive and aromatic primary amines are reluctant to formylation.

From a mechanistic perspective, preliminary stoichiometric transformations suggested that TBD is able to activate the $\mathrm{CO}_{2}$ molecule to yield adduct 3 (Scheme 9). ${ }^{34}$ In the presence of morpholine, $\mathbf{3}$ is transformed into salt $\mathbf{4}$ in which the carbamate anion is efficiently stabilized by the guanidinium cation $\mathrm{TBDH}^{+}$through $\mathrm{H}$-bonds. Reacting 4 with one equivalent of phenylsilane affords the formamide product, the silanol as a by-product and the active TBD base. ${ }^{33}$ For comparison, alcohols $\left(\mathrm{MeOH}, \mathrm{iPrOH}\right.$ and $\left.\mathrm{PhCH}_{2} \mathrm{OH}\right)$ also react with 3 and the formation of the corresponding carbonate salt was observed. Unfortunately, the reduction of these carbonates to the alkylformates was not achieved and the alcohol function was released as silyl ether.

Importantly, Zhang, Ying et al. demonstrated in 2009 that $\mathrm{N}$-heterocyclic carbenes (NHCs) were efficient catalysts in the hydrosilylation of $\mathrm{CO}_{2}$ to methoxysilanes, also at room temp- 

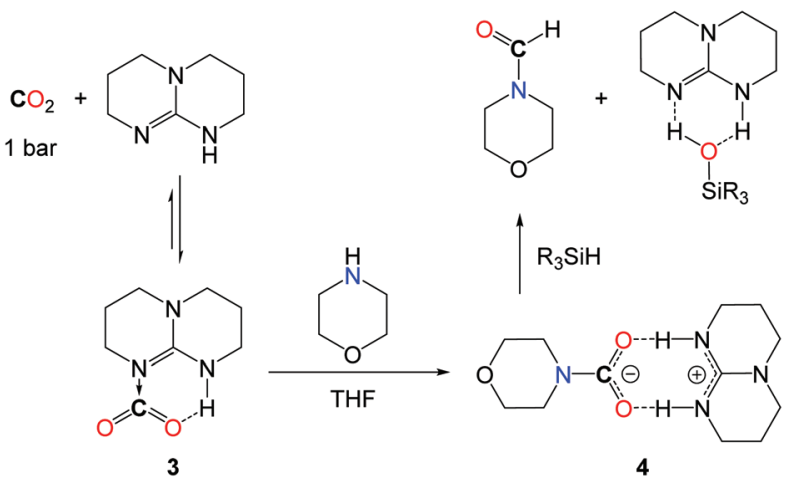

Scheme 9 Mechanistic investigation for the TBD-catalyzed formylation of morpholine.

erature. ${ }^{35}$ Inspired by this seminal work, our group has demonstrated that NHCs are able to promote the formylation of a wide scope of $\mathrm{N}-\mathrm{H}$ bonds, with $\mathrm{CO}_{2}$ and hydrosilanes (Scheme 8, II). ${ }^{36}$ Using IPr as the most reactive organocatalyst, primary and secondary amines were quantitatively converted to their formamides, at room temperature. Notably, both $\mathrm{N}-\mathrm{H}$ bonds of aniline derivatives could be formylated and the transformation was also extended to more fragile substrates such as imines, hydrazines, hydrazones and N-heterocycles. Overall, IPr is about 2000 times more reactive than TBD and this increased catalytic activity enabled the use of less reactive hydrosilanes in the formylation reaction. In fact, polymethylhydrosiloxane (PMHS) is a highly attractive reductant in hydrosilylation chemistry, as it is a cost-efficient, non-toxic and airstable by-product of the silicone industry. Importantly, PMHS proved to be an efficient reductant in the NHC-catalyzed formylation of $\mathrm{N}-\mathrm{H}$ bonds with $\mathrm{CO}_{2}$. More recently, a copper/ diphosphine catalytic system has been developed by the group of Baba. ${ }^{37}$ This system has the advantage of using an earth abundant metal catalyst, namely a $1: 3$ mixture of $\mathrm{Cu}(\mathrm{OAc})_{2} \cdot \mathrm{H}_{2} \mathrm{O}$ and dppBz (dppBz: 1,2-bis(diphenylphosphino)benzene). With low catalyst loadings $(<0.1 \mathrm{~mol} \%)$, TONs up to 9000 could be achieved. Moreover, an atmospheric pressure of $\mathrm{CO}_{2}(1 \mathrm{bar})$ was sufficient for the formylation of amines using PMHS as a reductant, at $80{ }^{\circ} \mathrm{C}$ (Scheme 8, III). Primary and secondary amines could be reacted in moderate to very good yields. Although our group has shown that $\mathrm{Fe}(\mathrm{acac})_{2}$ supported by $\mathrm{P}\left(\mathrm{C}_{2} \mathrm{H}_{4} \mathrm{PPh}_{2}\right)_{3}$ is an efficient formylation catalyst at room temperature with 1 bar $\mathrm{CO}_{2}$, this iron system is limited to $\mathrm{PhSiH}_{3}$ and milder PMHS and TMDS hydrosilanes are unreactive under these conditions (Scheme $8, \mathbf{I V}){ }^{38}$

In 2013, the group of Mizuno followed a two step procedure to convert $\mathrm{CO}_{2}$ to formamides (Scheme $10, \mathrm{I}$ ) ${ }^{39}$ The hydrosilylation of $\mathrm{CO}_{2}$ was first accomplished with dimethylphenylsilane, using a catalytic amount of $\mathrm{Rh}_{2}(\mathrm{OAc})_{4}(0.25 \mathrm{~mol} \%)$ and $\mathrm{K}_{2} \mathrm{CO}_{3}(0.5 \mathrm{~mol} \%)$. The resulting formoxysilane was subsequently trapped by addition of an amine. Although this reaction afforded formamides in low to moderate yields, the two step strategy allowed for the formation of a secondary alcohol by replacing the amine with a Grignard reagent.

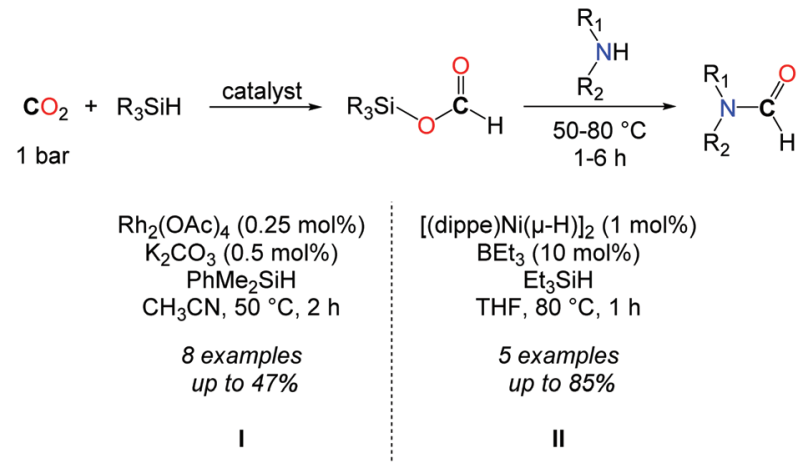

Scheme 10 Two-step procedure for the catalytic formylation of amines using $\mathrm{CO}_{2}$ and hydrosilanes.

In continuity with the work of Mizuno, the group of Garcia reported afterwards a Ni-based catalyst for the hydrosilylation of $\mathrm{CO}_{2} \cdot{ }^{40}[(\text { dippe }) \mathrm{Ni}-(\mu-\mathrm{H})]_{2}$ (dippe: 1,2-bis(diisopropylphosphino)ethane) was used in THF at $80{ }^{\circ} \mathrm{C}$ as a well-defined $\mathrm{Ni}$-catalyst. In order to achieve higher activity towards the hydrosilylation of $\mathrm{CO}_{2}$, catalytic amounts of a Lewis base $\left(\mathrm{Et}_{3} \mathrm{~B}\right.$, $10 \mathrm{~mol} \%$ ) were needed, so as to polarize the $\mathrm{Si}-\mathrm{H}$ and/or the carbonyl $\mathrm{C}=\mathrm{O}$ bonds. Under these conditions, formamides could be obtained in very good yields starting from primary amines (Scheme 10, II). Nevertheless, secondary amines proved to be much less reactive in this approach and the formylation of dibenzylamine was limited to $47 \%$, after $5 \mathrm{~h}$.

The reduction of $\mathrm{CO}_{2}$ using hydroboranes (namely 9-BBN, pinBH and catBH) has been recently discovered by the group of Guan, using nickel(II) complexes supported by phosphinepinceur ligands (Scheme 11, I). ${ }^{41}$ In 2012, Sabo-Etienne, Bontemps and co-workers reported an active ruthenium(II) hydride complex able to promote the same reaction and reaction intermediates such as formoxyboranes, formaldehyde and a $\mathrm{C}_{2}{ }^{-}$ compound ( pinBOCH $\mathrm{H}_{2} \mathrm{OCOH}$ ) were identified in the reduction of $\mathrm{CO}_{2}$ to methoxyborane (Scheme 11, II) ${ }^{42}$ Remarkably, the authors were able to trap the transient formaldehyde intermediate with the bulky 2,6-bis(diisopropyl)aniline to afford the corresponding imine $\left(2,6-\mathrm{iPr}_{2}-\mathrm{C}_{6} \mathrm{H}_{3}\right) \mathrm{N}=\mathrm{CH}_{2}{ }^{43}$

In this context, Shintani and Nozaki showed that hydroboranes could serve as efficient reductants for the formylation of amines with $\mathrm{CO}_{2}$, albeit within a two-step strategy. ${ }^{44}$ Thus, a

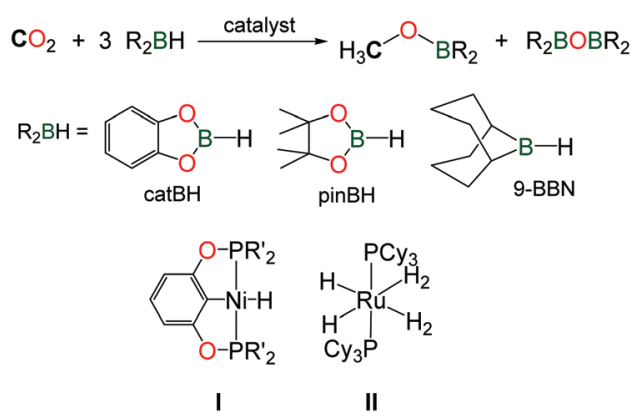

Scheme 11 Reported catalysts for the reduction of $\mathrm{CO}_{2}$ to methanol using hydroboranes. 


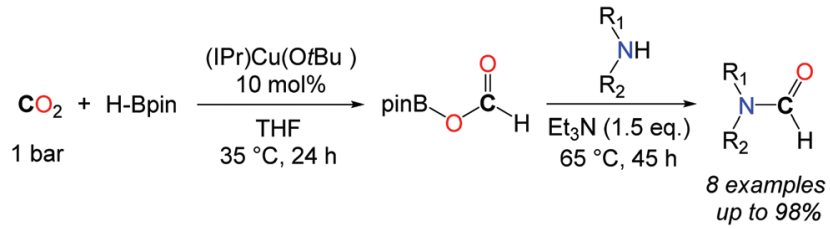

Scheme 12 Formylation of amine via a catalytic hydroboration of $\mathrm{CO}_{2}$.

$\mathrm{NHC} / \mathrm{Cu}^{\mathrm{I}}$ system has been successfully employed for the mono formylation of primary as well as secondary amines in very good to excellent isolated yields (Scheme 12). The system relies on the use of pinacolborane in addition to the discrete $\mathrm{IPrCu}-$ $(\mathrm{O} t \mathrm{Bu})$ complex, present in $10 \mathrm{~mol} \%$. The reactions were carried out in THF at $35{ }^{\circ} \mathrm{C}$ for $24 \mathrm{~h}$ followed by the addition of the amine in the presence of an additional base $\left(\mathrm{NEt}_{3}\right)$. The corresponding formamides were obtained after $45 \mathrm{~h}$ at $65^{\circ} \mathrm{C}$.

\section{Synthesis of formamidine derivatives using $\mathrm{CO}_{2}$}

In the search for novel catalytic processes able to utilize $\mathrm{CO}_{2}$ as a $\mathrm{C}_{1}$ building block in organic synthesis, the complete deoxygenation of $\mathrm{CO}_{2}$ is of interest to access non-carbonyl compounds. Indeed, the scope of chemical functions available from $\mathrm{CO}_{2}$ is mostly limited to molecules in which at least one $\mathrm{C}-\mathrm{O}$ bond from $\mathrm{CO}_{2}$ is retained and the complete reduction of $\mathrm{CO}_{2}$ to $\mathrm{CH}_{4}$ is one of the rare catalytic processes able to promote the deoxygenation of $\mathrm{CO}_{2}{ }^{45}$ The recent success obtained for the conversion of $\mathrm{CO}_{2}$ to formamides, under mild conditions, enabled the utilization of this transformation in cascade strategies. Indeed, formamide derivatives can act as electrophiles and, for example, the condensation of a primary amine $\mathrm{RNH}_{2}$ to a formamide $\mathrm{R}_{2}^{\prime} \mathrm{NCHO}$ is a route to the synthesis of formamidines $\mathrm{RN}=\mathrm{C}(\mathrm{H}) \mathrm{NR}_{2}^{\prime}$, in the presence of hard drying agents, such as phosphorus oxychloride, trifluoroacetic anhydride and thionyl chloride. In 2013, our group and the group of Liu demonstrated independently that, starting from $o$-phenylenediamines, benzimidazoles were formed by two different catalytic systems (Schemes 13 and 14). ${ }^{46}$

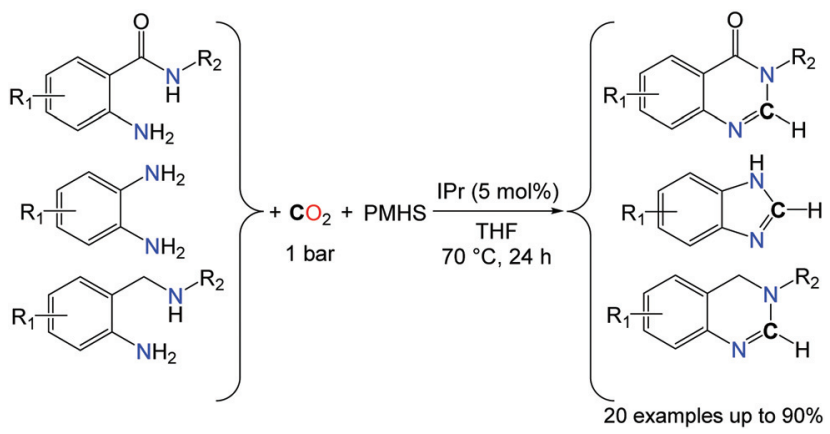

Scheme 13 Synthesis of formamidine derivatives using $\mathrm{CO}_{2}$ and hydrosilanes as reductants.

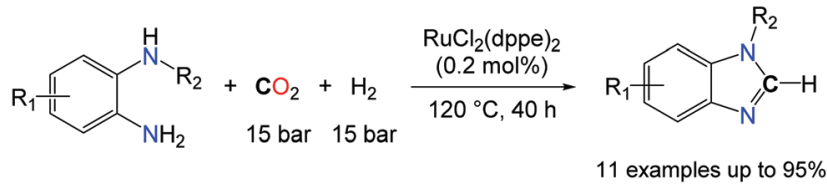

Scheme 14 Synthesis of formamidine derivatives using $\mathrm{CO}_{2}$ and $\mathrm{H}_{2}$ as reductants.

Using the NHC-catalyzed formylation of amines with $\mathrm{CO}_{2}$ and hydrosilanes, very good yields and selectivities could be achieved for the synthesis of benzimidazole rings, after the optimisation of the reaction temperature $\left(70{ }^{\circ} \mathrm{C}\right.$ instead of room temperature) in the presence of the PMHS as the reductant. The reactions were carried out in THF under 1 bar of $\mathrm{CO}_{2}$ (Scheme 13). ${ }^{46 a}$ It is noteworthy that the methodology is not limited to the formation of benzimidazole derivatives and 6-membered N-heterocyclic compounds could be obtained in good yields with anthranilamide and 2-aminobenzylamine derivatives. In fact, both amide and amine $\mathrm{N}-\mathrm{H}$ bonds were found reactive in anthranilamides, leading to the formation of quinazolinones in the presence of $\mathrm{CO}_{2}$ and PMHS. Similarly, 3,4-dihydroquinazoline heterocycles were synthesized from their corresponding 2-aminobenzylamines.

In contrast, Liu and co-workers capitalized on the formylation of $\mathrm{N}-\mathrm{H}$ bonds with $\mathrm{CO}_{2} / \mathrm{H}_{2}$ as an entry to formamidine derivatives. ${ }^{46 b}$ Utilizing $\mathrm{RuCl}_{2}$ (dppe $)_{2}(0.2 \mathrm{~mol} \%)$ as a catalyst, benzimidazoles were formed in very good to excellent yields from $o$-phenylenediamines substituted with either electron withdrawing or donating groups. Nonetheless, the utilization of $\mathrm{H}_{2}$ as a reductant comes with a kinetic prize and enables only the preparation of benzimidazoles. It also imposes harsh reaction conditions, as the catalytic transformation proceeds at $120{ }^{\circ} \mathrm{C}$ under elevated gas pressures (mixture of $\mathrm{CO}_{2}$ and $\mathrm{H}_{2}$ : $150 \mathrm{bar}$ ). The intermolecular version of these transformations would be desirable to access formamidines from two equivalents of primary amines and $\mathrm{CO}_{2}$, in the presence of a reductant. So far, hydrosilanes have appeared as the most promising reductant to tackle this challenge and $N, N^{\prime}$-diphenyl-formamidine could be successfully obtained in $44 \%$ yield, from two equivalents of $\mathrm{PhNH}_{2}$ in the presence of an atmosphere of $\mathrm{CO}_{2}$ and 0.6 equiv. $\mathrm{PhSiH}_{3}$, using $5.0 \mathrm{~mol} \% \mathrm{TBD}^{46 a}$ It is likely, however, that this transformation follows a different route as TBD is unable to convert aniline to its formamide. Given the recent developments in the successful reduction of urea derivatives to formamidines, ${ }^{47}$ it is probable that TBD favours the formation of $N, N^{\prime}$-diphenyl-urea which is consecutively reduced by the hydrosilane.

\section{Methylation of $\mathrm{N}-\mathrm{H}$ bonds with carbon dioxide}

Among nitrogen organic chemicals featuring $\mathrm{C}_{1}$ chemical groups, methylamines are the most reduced species with a $\mathrm{N}-\mathrm{CH}_{3}$ carbon atom in the $-\mathrm{II}$ oxidation state. Current methyl- 
ation methodologies rely on the use of formaldehyde in the presence of a reductant for the formation of the $\mathrm{N}-\mathrm{CH}_{3}$ backbones and, in the laboratory, hazardous alkylating agents such as methyliodide, dimethylsulfate and dimethylcarbonate are preferred. ${ }^{48}$ Utilizing $\mathrm{CO}_{2}$ as a carbon source for the methylation of $\mathrm{N}-\mathrm{H}$ bonds would therefore improve the sustainability of methylamines by providing an alternative route to their petrochemical synthesis. ${ }^{49}$ Such a transformation requires the use of a mild reductant and an efficient catalyst able to promote the 6-electron reduction of $\mathrm{CO}_{2}$ and facilitate the formation of a $\mathrm{C}-\mathrm{N}$ bond. Early investigations on the synthesis of DMF from $\mathrm{CO}_{2}, \mathrm{H}_{2}$ and dimethylamine led to the observation of trimethylamine (TMA) as a side-product. ${ }^{17}$ The authors assumed that TMA resulted from the catalytic hydrogenation of DMF. Yet, as proposed by Vaska and co-workers, the scrambling of an alkyl group between two amine molecules or between an amine and an amide is possible and could account for the formation of TMA, upon reductive functionalization of $\mathrm{CO}_{2}$ with $\mathrm{Me}_{2} \mathrm{NH}$ and $\mathrm{H}_{2}$.

In 1995, Baiker et al. reported the first synthesis of methylamines, in a fixed-bed microreactor, using a mixture of ammonia, $\mathrm{H}_{2}$ and $\mathrm{CO}_{2}$ and heterogeneous $\mathrm{Cu} / \mathrm{Al}_{2} \mathrm{O}_{3}$ catalysts. ${ }^{50}$ Nevertheless, very harsh reaction conditions were required, as the experiments were conducted between 240 and $280{ }^{\circ} \mathrm{C}$ under 6 bar of $\mathrm{NH}_{3}-\mathrm{CO}_{2}-\mathrm{H}_{2}$ (ratio 1/1/3) (Scheme 15). The formation of methylamine (MA) is favoured at high temperatures together with the production of CO via the reverse water gas shift reaction. Importantly, the concentration of ammonia in the gas mixture has a significant impact on the selectivity and, at $240{ }^{\circ} \mathrm{C}$, MA is favoured at high concentrations while low concentrations of $\mathrm{NH}_{3}$ facilitate the accumulation of TMA.

Two plausible pathways were proposed for the catalytic mechanism depending on the carbon species involved in the formation of the $\mathrm{C}-\mathrm{N}$ bond. ${ }^{51}$ Indeed, methanol, obtained by hydrogenation of $\mathrm{CO}_{2}$, can undergo an amination step to afford the methylamine product and a molecule of water. Alternatively, a $\mathrm{C}^{0}$ intermediate corresponding to the adsorption of formaldehyde at the catalyst surface can account for the formation of an imine intermediate, which is readily hydrogenated to its methylamine. A subsequent work was devoted to testing various types of metal-alumina catalysts $(\mathrm{Cu}, \mathrm{Ag}, \mathrm{Pt}, \mathrm{Ni}$, $\mathrm{Co}, \mathrm{Fe}$ ), under the same reactions conditions, so as to improve the catalytic activities and selectivities. ${ }^{52}$ The best amine production rates were obtained with $\mathrm{Cu}$-based catalysts. $\mathrm{Cu}-\mathrm{Mg}-\mathrm{Al}$ mixed oxides showed interesting activities in this reaction at $280{ }^{\circ} \mathrm{C}$ for the same gas composition. ${ }^{53}$ While good selectivities were obtained in all cases for the formation of MA $(>79 \%)$, the catalytic activity is directly controlled by the

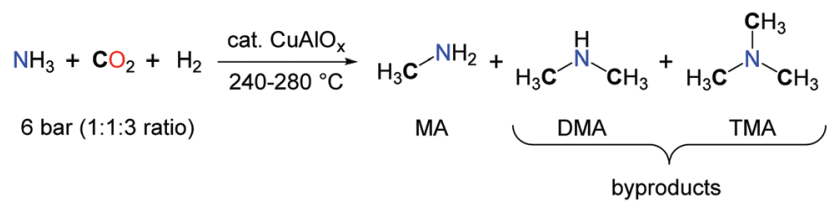

Scheme 15 Methylation of ammonia catalyzed by a CuAlO catalyst.

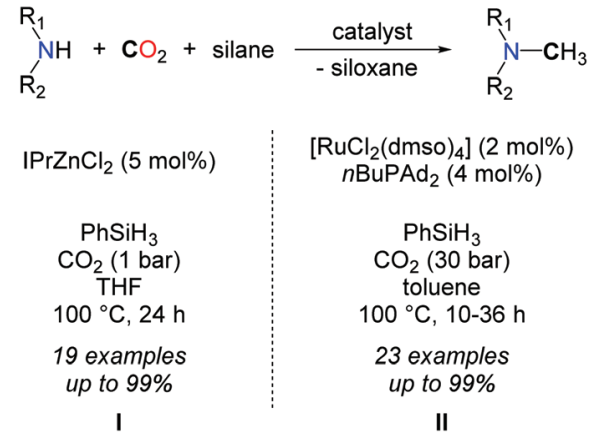

Scheme 16 Catalytic systems for the methylation of amines using $\mathrm{CO}_{2}$ and hydrosilanes.

content of aluminium in the catalytic system. The rate of methylamine production is tripled when the molecular ratio of aluminium is increased from 25 to $33 \%$ in the catalyst $(0.24 \mathrm{vs}$ $0.67 \mathrm{~mol} \mathrm{~kg}_{\text {cata }}^{-1} \mathrm{~h}^{-1}$ ).

In 2013, our group demonstrated that replacing $\mathrm{H}_{2}$ with a more polar hydrosilane reductant enables the methylation of a large scope of amines, under mild reaction conditions, namely with 1 to 5 bar $\mathrm{CO}_{2}$ at $100{ }^{\circ} \mathrm{C}($ Scheme $16, \mathrm{I}) .{ }^{54}$ Using a homogeneous system, based on a discrete $\mathrm{NHC} / \mathrm{Zn}$ catalyst a variety of primary and secondary aromatic and aliphatic amines were successfully methylated, from $\mathrm{CO}_{2}$ as the carbon source and $\mathrm{PhSiH}_{3}$ as the reductant. The source of the extra methyl group was established unambiguously using ${ }^{13} \mathrm{C}$-labelled $\mathrm{CO}_{2}$. While bare $\mathrm{ZnCl}_{2}$ and $\mathrm{ZnEt}_{2}$ salts showed a modest catalytic activity in the methylation of $\mathrm{N}$-methylaniline, a set of NHCs, phosphines and $N$-heterocycles were screened as supporting ligands to enhance the catalytic activity and NHCs afforded the highest conversions. It is likely however that the carbene ligands increase the stability of the $\mathrm{Zn}$ catalyst rather than its activity, as it was recently demonstrated that $\mathrm{ZnH}_{2}$ is efficiently stabilized using NHCs. ${ }^{55}$

Preliminary mechanistic investigations were conducted so as to identify the main intermediates involved in the methylation reaction. Kinetic data and monitoring of the product distribution over time showed that formamides are the main intermediates. In fact, the Hammett correlation, studied for substituted $N$-methylaniline reagents, reveals that the mechanism involves two steps with opposite electronic demands at the nitrogen center. While the formylation of the $\mathrm{N}-\mathrm{H}$ bond is favoured by electron-donating groups, the reduction of the resulting formamide is facilitated in the presence of electronwithdrawing groups on the aryl ring (Scheme 17). Notably, this mechanism is consistent with the known catalytic activity of zinc complexes in the hydrosilylation of amides. ${ }^{56}$ As a result

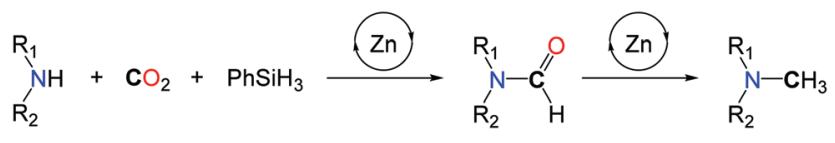

Scheme 17 Proposed mechanism for the methylation of amines with $\mathrm{IPrZnCl}$. 


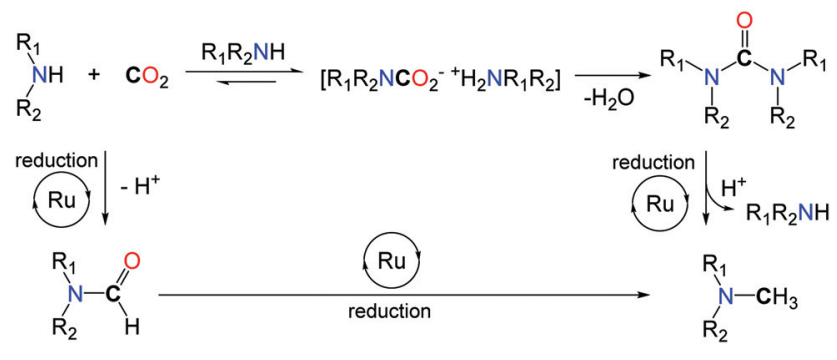

Scheme 18 Proposed mechanism for the Ru-catalyzed methylation of amines.

of this mechanism, secondary aliphatic amines are less reactive than aromatic amines and require longer reaction times (up to $72 \mathrm{~h}$ ) to undergo the methylation of $\mathrm{N}-\mathrm{H}$ bonds, because the hydrosilylation of the corresponding formamide is significantly slower.

Shortly afterwards, an elegant procedure has been published by the group of Beller to promote the same reaction. ${ }^{57}$ Once again hydrosilanes (namely $\mathrm{PhSiH}_{3}$ ) were used as reductants in this case in association with the ruthenium complex $\mathrm{RuCl}_{2}(\mathrm{dmso})_{4} \quad(2 \mathrm{~mol} \%)$ and CataCXium ${ }^{\circledR A}$ as a ligand $\left(n \mathrm{BuPAd}_{2}, 4 \mathrm{~mol} \%\right)$. Overall, the scope and reaction conditions are very similar to the zinc system and the reactions were carried out in toluene at $100{ }^{\circ} \mathrm{C} .30$ bar of $\mathrm{CO}_{2}$ were required to obtain good to excellent yields with primary and secondary amines (Scheme 16, II). Moreover, the authors successfully demonstrated that their procedure enables the selective methylation of the amine function when amino alcohols are used. Indeed, $\mathrm{N}$-methylephedrine was obtained in good yields $(73 \%)$ and high selectivity $(>7: 1)$ starting from ephedrine.

Based on mechanistic investigations, the authors postulate two possible pathways (Scheme 18). The ruthenium(II) catalyst may follow a route analogous to the zinc system and promote, first, the formylation of the $\mathrm{N}-\mathrm{H}$ bond, followed by reduction of the formamide with $\mathrm{PhSiH}_{3}$. Alternatively, functionalization of $\mathrm{CO}_{2}$ with two equivalents of the amine reagent can afford a urea derivative, under dehydrating conditions. Consecutive hydrosilylation promoted by the $\mathrm{Ru}$ catalyst results in the formation of the methylamine product.

In this context control experiments were performed, starting from 1,2-ethylenediamines, and the two pathways were found viable. Additionally, the catalyst developed for the methylation of amines showed a catalytic activity in the hydrosilylation of ureas, under the applied reaction conditions.

Searching for earth abundant catalysts for the reduction of $\mathrm{CO}_{2}$, our group reported in 2014 the first iron catalysts able to promote the hydrosilylation of carbon dioxide. In the presence of $\mathrm{P}\left(\mathrm{C}_{2} \mathrm{H}_{4} \mathrm{PPh}_{2}\right)_{3}$ as a supporting ligand, $\mathrm{Fe}(\mathrm{acac})_{2}$ catalyzes the formylation of amines with $\mathrm{PhSiH}_{3}$ and 1 bar $\mathrm{CO}_{2}$ at room temperature while it facilitates the methylation of aniline derivatives at $100{ }^{\circ} \mathrm{C} .{ }^{38}$

The use of $\mathrm{H}_{2}$ as a reductant for the methylation of amines with $\mathrm{CO}_{2}$ is highly desirable for large scale applications and the production of bulk chemicals from $\mathrm{CO}_{2}$. Yet, beyond the
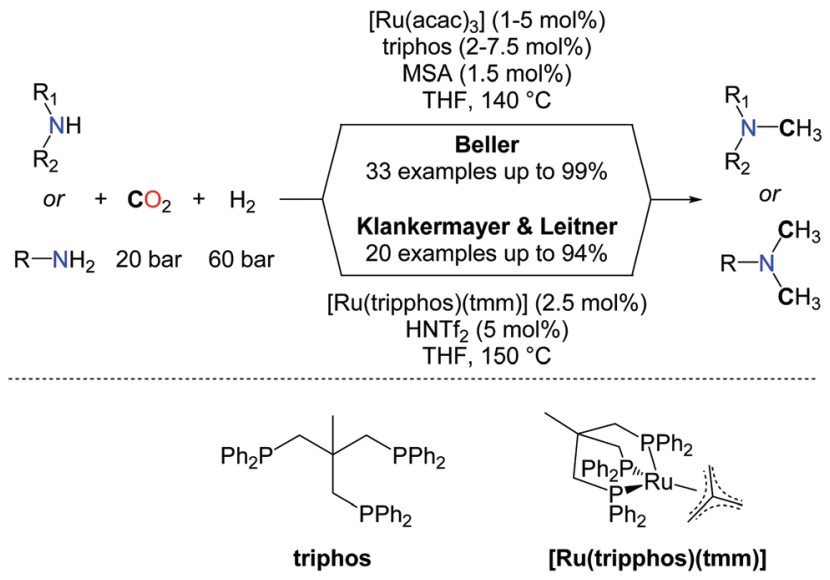

Scheme 19 Ru-catalyzed methylation of amines using $\mathrm{H}_{2}$ and $\mathrm{CO}_{2}$.

promising results obtained by the Baiker group (vide supra), efficient catalysts able to promote the methylation of a large scope of $\mathrm{N}-\mathrm{H}$ bonds have remained elusive, until very recently. In 2013, Klankermayer et al. and Beller et al. reported independently the first homogeneous catalysts able to convert amines to methylamines using $\mathrm{CO}_{2} / \mathrm{H}_{2}$ as a source of the $\mathrm{N}-\mathrm{CH}_{3}$ group (Scheme 19)..$^{58}$ The two catalytic systems are very similar and rely on ruthenium triphospine complexes activated by a catalytic amount of an acid, using the same ratio of $\mathrm{CO}_{2}$ and hydrogen (20/60 bar). The reactions for the mono or double methylations starting from secondary and primary amines are performed at nearly the same temperature $\left(140-150^{\circ} \mathrm{C}\right)$. Based on detailed mechanistic investigations, Klankermayer and Leitner developed over the last years a highly efficient molecular system, in catalytic reduction chemistry, consisting of the activation of a well-defined (triphos) $\mathrm{Ru}(\mathrm{tmm})$ (tmm=trimethylenemethane) complex by an acid co-catalyst such as trifluoromethanesulfonimide $\left(\mathrm{HNTf}_{2}\right)$. This system showed a very good catalytic activity in the methylation of amines with $\mathrm{CO}_{2} / \mathrm{H}_{2} \cdot{ }^{59}$

In the system developed by Beller and co-workers, $\mathrm{Ru}(\mathrm{acac})_{2}$ mixed with triphos(1,1,1-tris(diphenylphosphinomethyl)ethane) as the ligand is used in the presence of catalytic amounts of methanesulfonic acid (MSA, $1.5 \mathrm{~mol} \%$ ) to obtain the methylated amines in good to excellent yields (Scheme 19). Notably, several other ligands were tested under the same reaction conditions but only traces of the product were observed. Moreover the mono-methylation of amines could be achieved in the system developed by Beller by taking advantage of the electronic and steric hindrance of substituted anilines.

From a mechanistic perspective, both groups conclude that a sequential formylation/amide reduction is the most favourable route in the methylation reaction, and the formation of formamide intermediates was clearly demonstrated. As a consequence, aliphatic amines exhibit a lower reactivity than aromatic amines, presumably because the reduction of the corresponding formamide intermediate is more difficult, in the absence of an aromatic substituent. However, the Beller's group found that replacing the acid promoter with LiCl salt, together with increased catalyst loadings, enabled the quanti- 


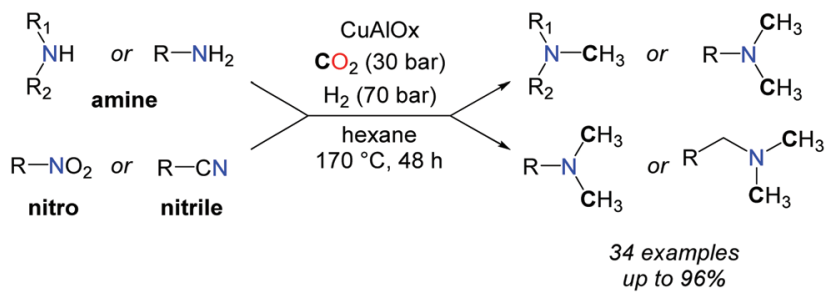

Scheme 20 Methylation of amines with a heterogeneous $\mathrm{CuAlO}_{\mathrm{x}}$ system.

tative bismethylation of aliphatic primary amines, such as benzylamine. In parallel, Klankermayer et al. successfully demonstrated the tandem hydrogenation and N-methylation of acetanilide yielding the unsymmetrical methyl/alkyl anilines. The chemoselectivity of the reaction was investigated and the mono-methylation of diamines shows promising selectivity. Despite the reductive conditions, the methylation of primary anilines is tolerant to ether, ester, hydroxyl, and carbon-halogen functionalities. Nonetheless, $\mathrm{C}=\mathrm{C}$ double bonds might be reduced under the applied conditions, depending on the substitution scheme of the unsaturation. Indeed, Klankermayer et al. observed that the $\mathrm{C}=\mathrm{C}$ bond in indole is hydrogenated upon methylation. In contrast, Beller's system enables methylation of nortriptyline, leaving the trisubstituted olefin untouched, and this latter reaction was utilized for the synthesis of ${ }^{13} \mathrm{C}$-labelled amitriptyline from ${ }^{13} \mathrm{CO}_{2}$.

More recently, the group of Shi reported a $\mathrm{CuAlO}_{x}$ catalyst able to promote the methylation of amines with $\mathrm{CO}_{2}$ and $\mathrm{H}_{2}$, albeit with high catalyst loadings. ${ }^{60}$ Primary and secondary aromatic and aliphatic amines as well as nitriles and nitroarenes were converted to methylamines, at elevated temperatures (up to $170{ }^{\circ} \mathrm{C}$ ) and pressures $\left(\mathrm{H}_{2} / \mathrm{CO}_{2}\right.$ : 60-70/30 bar) (Scheme 20).

\section{Conclusions and outlook}

The utilization of amines as bases to facilitate the hydrogenation of $\mathrm{CO}_{2}$ to formates led to the recognition that $\mathrm{CO}_{2}$ could serve as a $\mathrm{C}_{1}$ building block for the formylation of $\mathrm{N}-\mathrm{H}$ bonds. Developed in the 1980 s, this reaction has been mostly utilized for the conversion of dimethylamine to DMF and its scope remained quite limited, despite the design of novel metal catalysts. In 2012, the use of hydrosilanes in the formylation of amines with $\mathrm{CO}_{2}$ was unveiled. The hydrosilane reductant exhibits a kinetic advantage over $\mathrm{H}_{2}$ and enables the formylation of a wide scope of amines with organic catalysts working at room temperature and 1 bar $\mathrm{CO}_{2}$. Hydrosilanes and hydroboranes have a limited availability and must be utilized as non-renewable stoichiometric reagents. Nevertheless, they possess a mild reduction potential well-suited for $\mathrm{CO}_{2}$ reduction and they exhibit an increased chemoselectivity with respect to $\mathrm{H}_{2}$. This chemical behaviour allowed for the design of novel processes to promote the complete deoxygenation of $\mathrm{CO}_{2}$ to formamidine and methylamine derivatives, and the
$\mathrm{H}_{2}$-versions of these transformations were unveiled shortly afterwards, using ruthenium catalysts. Overall, while organic ureas were privileged targets for $\mathrm{CO}_{2}$ conversion with amines, the reductive functionalization of $\mathrm{CO}_{2}$ has significantly opened the spectrum of nitrogen compounds available from this oxidized carbon feedstock.

Future efforts will surely concern the design of novel catalysts based on earth abundant metal ions or organic molecules, with the aim of increasing the catalytic activity of these new transformations, at mild temperature and pressure. A better understanding of the mechanisms at play in the reductive functionalization of $\mathrm{CO}_{2}$ is a venue to explore, and to facilitate the design of next generation catalysts. Such knowledge would also help improve the chemo-selectivity of the reduction of $\mathrm{CO}_{2}$, as the presence of reducible chemical groups, such as aldehydes and ketones, has been problematic so far. Nonetheless, these efforts are motivated by the number of potential applications involving these novel reactions. While the conversion of $\mathrm{NH}_{3}-\mathrm{CO}_{2}-\mathrm{H}_{2}$ mixtures could provide meaningful alternatives to the production of bulk chemicals such as methylamine, dimethylamine, trimethylamine, and their formamide derivatives, these technologies will also be relevant in the synthesis of fine chemicals. Although challenging, ${ }^{11} \mathrm{C}$ and ${ }^{14} \mathrm{C}$ labelled molecules are important targets, as ${ }^{11} \mathrm{CO}_{2}$ and ${ }^{14} \mathrm{CO}_{2}$ are the primary sources of these C-isotopes and $\mathrm{N}-\mathrm{CHO}$, $\mathrm{N}-\mathrm{CH}=\mathrm{N}$ and $\mathrm{N}-\mathrm{CH}_{3}$ backbones are commonly found in nitrogen heterocycles and bioactive compounds.

\section{Acknowledgements}

For financial support of this work, we acknowledge the CEA, CNRS, ADEME, the CHARMMMAT Laboratory of Excellence and the European Research Council (ERC Starting Grant Agreement n.336467). T.C. thanks the Foundation Louis D. - Institut de France for its formidable support.

\section{Notes and references}

1 Carbon Dioxide: Projected emissions and concentrations, International Panel on Climate Change, 2013.

2 (a) P. Markewitz, W. Kuckshinrichs, W. Leitner, J. Linssen, P. Zapp, R. Bongartz, A. Schreiber and T. E. Muller, Energy Environ. Sci., 2012, 5, 7281; (b) D. Stolten and V. Scherer, Efficient Carbon Capture for Coal Power Plants, Wiley-VCH, 2011.

3 Tracking industrial energy efficiency and CO2 emissions International Energy Agency, Paris, France, 2007.

4 (a) M. Aresta, Carbon Dioxide as Chemical Feedstock, WileyVCH, Weinheim, 2010; (b) K. Huang, C.-L. Sun and Z.-J. Shi, Chem. Soc. Rev., 2011, 40, 2435; (c) T. Sakakura, J.-C. Choi and H. Yasuda, Chem. Rev., 2007, 107, 2365; (d) D. J. Darensbourg, Chem. Rev., 2007, 107, 2388; (e) T. Sakakura and K. Kohno, Chem. Commun., 2009, 1312; 
(f) I. Omae, Coord. Chem. Rev., 2012, 256, 1384; (g) Y. Tsuji and T. Fujihara, Chem. Commun., 2012, 48, 9956.

5 Z. Z. Yang, L. N. He, J. Gao, A. H. Liu and B. Yu, Energy Environ. Sci., 2012, 5, 6602.

6 (a) E. E. Benson, C. P. Kubiak, A. J. Sathrum and J. M. Smieja, Chem. Soc. Rev., 2009, 38, 89; (b) W. Wang, S. Wang, X. Ma and J. Gong, Chem. Soc. Rev., 2011, 40, 3703; (c) R. E. Rodriguez-Lugo, M. Trincado, M. Vogt, F. Tewes, G. Santiso-Quinones and H. Grutzmacher, Nat. Chem., 2013, 5, 342; (d) M. Nielsen, E. Alberico, W. Baumann, H. J. Drexler, H. Junge, S. Gladiali and M. Beller, Nature, 2013, 495, 85; (e) N. MacDowell, N. Florin, A. Buchard, J. Hallett, A. Galindo, G. Jackson, C. S. Adjiman, C. K. Williams, N. Shah and P. Fennell, Energy Environ. Sci., 2010, 3, 1645; (f) P. G. Jessop, T. Ikariya and R. Noyori, Chem. Rev., 1995, 95, 259; (g) W. Leitner, Angew. Chem., Int. Ed. Engl., 1995, 34, 2207;

(h) A. Boddien, D. Mellmann, F. Gartner, R. Jackstell, H. Junge, P. J. Dyson, G. Laurenczy, R. Ludwig and M. Beller, Science, 2011, 333, 1733; (i) C. Federsel, A. Boddien, R. Jackstell, R. Jennerjahn, P. J. Dyson, R. Scopelliti, G. Laurenczy and M. Beller, Angew. Chem., Int. Ed., 2010, 49, 9777; (j) R. Tanaka, M. Yamashita and K. Nozaki, J. Am. Chem. Soc., 2009, 131, 14168; (k) K. Mori, H. Yamashita and M. Anpo, RSC Adv., 2012, 2, 3165; (l) E. Balaraman, Y. Ben-David and D. Milstein, Angew. Chem., Int. Ed., 2011, 50, 11702; $(m)$ E. Balaraman, C. Gunanathan, J. Zhang, L. J. W. Shimon and D. Milstein, Nat. Chem., 2011, 3, 609; (n) R. W. Dorner, D. R. Hardy, F. W. Williams and H. D. Willauer, Energy Environ. Sci., 2010, 3, 884 .

7 E. A. Quadrelli, G. Centi, J. L. Duplan and S. Perathoner, Chemsuschem, 2011, 4, 1194.

8 Carbon Recycling International, 2014. See http://www. carbonrecycling.is.

9 R. W. Dorner, D. R. Hardy, F. W. Williams and H. D. Willauer, Catal. Commun., 2011, 15, 88.

10 (a) P. Braunstein, D. Matt and D. Nobel, Chem. Rev., 1988, 88, 747; (b) K. Huang, C. L. Sun and Z. J. Shi, Chem. Soc. Rev., 2011, 40, 2435.

11 S. Ding and N. Jiao, Angew. Chem., Int. Ed., 2012, 51, 9226.

12 H. Bipp and H. Kieczka, Formamides, in Ullmann's Encyclopedia of Industrial Chemistry, Wiley-VCH, 2000.

13 M. W. Farlow and H. Adkins, J. Am. Chem. Soc., 1935, 57, 2222.

14 P. Haynes, L. H. Slaugh and J. F. Kohnle, Tetrahedron Lett., 1970, 11, 365.

15 K. Kudo, H. Phala, N. Sugita and Y. Takezaki, Chem. Lett., 1977, 1495.

16 Y. Morimoto, Y. Fujiwara, H. Taniguchi, Y. Hori and Y. Nagano, Tetrahedron Lett., 1986, 27, 1809.

17 (a) S. Schreiner, J. Y. Yu and L. Vaska, Inorg. Chim. Acta, 1988, 147, 139; (b) S. Schreiner, J. Y. Yu and L. Vaska, J. Chem. Soc., Chem. Commun., 1988, 602.

18 L. Vaska, S. Schreiner, R. A. Felty and J. Y. Yu, J. Mol. Catal., 1989, 52, L11.
19 P. G. Jessop, Y. Hsiao, T. Ikariya and R. Noyori, J. Am. Chem. Soc., 1994, 116, 8851.

20 P. G. Jessop, Y. Hsiao, T. Ikariya and R. Noyori, J. Am. Chem. Soc., 1996, 118, 344.

21 O. Krocher, R. A. Koppel and A. Baiker, Chem. Commun., 1997, 453.

22 (a) O. Kröcher, R. A. Köppel and A. Baiker, J. Mol. Catal. A: Chem., 1999, 140, 185; (b) O. Krocher, R. A. Koppel, M. Froba and A. Baiker, J. Catal., 1998, 178, 284; (c) L. Schmid, M. Rohr and A. Baiker, Chem. Commun., 1999, 2303.

23 F. Liu, M. B. Abrams, R. T. Baker and W. Tumas, Chem. Commun., 2001, 433.

24 M. Minato, D. Y. Zhou, K. Sumiura, R. Hirabayashi, Y. Yamaguchi and T. Ito, Chem. Commun., 2001, 2654.

25 J. Liu, C. Guo, Z. Zhang, T. Jiang, H. Liu, J. Song, H. Fan and B. Han, Chem. Commun., 2010, 46, 5770.

26 C. Federsel, C. Ziebart, R. Jackstell, W. Baumann and M. Beller, Chem. - Eur. J., 2012, 18, 72.

27 C. Ziebart, C. Federsel, P. Anbarasan, R. Jackstell, W. Baumann, A. Spannenberg and M. Beller, J. Am. Chem. Soc., 2012, 134, 20701.

28 G. Süss-Fink, M. Langenbahn and T. Jenke, J. Organomet. Chem., 1989, 368, 103.

29 (a) L. Schmid, A. Canonica and A. Baiker, Appl. Catal., A, 2003, 255, 23; (b) L. Schmid, M. Schneider, D. Engel and A. Baiker, Catal. Lett., 2003, 88, 105.

30 P. Munshi, D. J. Heldebrant, E. P. McKoon, P. A. Kelly, C. C. Tai and P. G. Jessop, Tetrahedron Lett., 2003, 44, 2725.

31 X. Cui, Y. Zhang, Y. Deng and F. Shi, Chem. Commun., 2014, 50, 189.

32 H. Ishida, H. Tanaka, K. Tanaka and T. Tanaka, Chem. Lett., 1987, 597.

33 C. Das Neves Gomes, O. Jacquet, C. Villiers, P. Thuéry, M. Ephritikhine and T. Cantat, Angew. Chem., Int. Ed., 2012, 51, 187.

34 C. Villiers, J. P. Dognon, R. Pollet, P. Thuery and M. Ephritikhine, Angew. Chem., Int. Ed., 2010, 49, 3465.

35 S. N. Riduan, Y. Zhang and J. Y. Ying, Angew. Chem., Int. Ed., 2009, 48, 3322.

36 O. Jacquet, C. Das Neves Gomes, M. Ephritikhine and T. Cantat, J. Am. Chem. Soc., 2012, 134, 2934.

37 K. Motokura, N. Takahashi, D. Kashiwame, S. Yamaguchi, A. Miyaji and T. Baba, Catal. Sci. Technol., 2013, 3, 2392.

38 X. Frogneux, O. Jacquet and T. Cantat, Catal. Sci. Technol., 2014, 4, 1529.

39 S. Itagaki, K. Yamaguchi and N. Mizuno, J. Mol. Catal. A: Chem., 2013, 366, 347.

40 L. González-Sebastián, M. Flores-Alamo and J. J. García, Organometallics, 2013, 32, 7186.

41 S. Chakraborty, J. Zhang, J. A. Krause and H. Guan, J. Am. Chem. Soc., 2010, 132, 8872.

42 (a) S. Bontemps, L. Vendier and S. Sabo-Etienne, Angew. Chem., Int. Ed., 2012, 51, 1671; (b) S. Bontemps and S. Sabo-Etienne, Angew. Chem., Int. Ed., 2013, 52, 10253. 
43 S. Bontemps, L. Vendier and S. Sabo-Etienne, J. Am. Chem. Soc., 2014, 136, 4419.

44 R. Shintani and K. Nozaki, Organometallics, 2013, 32, 2459.

45 (a) A. A. Peterson and J. K. Norskov, J. Phys. Chem. Lett., 2012, 3, 251; (b) C. Oloman and H. Li, Chemsuschem, 2008, 1, 385; (c) T. Matsuo and H. Kawaguchi, J. Am. Chem. Soc., 2006, 128, 12362; (d) A. Berkefeld, W. E. Piers and M. Parvez, J. Am. Chem. Soc., 2010, 132, 10660; (e) S. Park, D. Bézier and M. Brookhart, J. Am. Chem. Soc., 2012, 134, 11404; $(f)$ M. Khandelwal and R. J. Wehmschulte, Angew. Chem., Int. Ed., 2012, 51, 7323; (g) P. G. Jessop, F. Joo and C. C. Tai, Coord. Chem. Rev., 2004, 248, 2425.

46 (a) O. Jacquet, C. Das Neves Gomes, M. Ephritikhine and T. Cantat, ChemCatChem, 2013, 5, 117; (b) B. Yu, H. Zhang, Y. Zhao, S. Chen, J. Xu, C. Huang and Z. Liu, Green Chem., 2013, 15, 95.

47 J. Pouessel, O. Jacquet and T. Cantat, ChemCatChem, 2013, 5, 3552 .

48 (a) W. Eschweiler, Ber. Dtsch. Chem. Ges., 1905, 880; (b) H. T. Clarke, H. B. Gillespie and S. Z. Weisshaus, J. Am. Chem. Soc., 1933, 55, 4571; (c) E. Farkas and C. J. Sunman, J. Org. Chem., 1985, 50, 1110; (d) F. Fache, L. Jacquot and M. Lemaire, Tetrahedron Lett., 1994, 35, 3313; (e) J. R. Harding, J. R. Jones, S.-Y. Lu and R. Wood, Tetrahedron Lett., 2002, 43, 9487.

49 A. Tlili, X. Frogneux, E. Blondiaux and T. Cantat, Angew. Chem., Int. Ed., 2014, 53, 2543.

50 S. V. Gredig, R. A. Koeppel and A. Baiker, J. Chem. Soc., Chem. Commun., 1995, 73.

51 S. V. Gredig, R. Koeppel and A. Baiker, Catal. Today, 1996, 29, 339.
52 S. V. Gredig, R. Koeppel and A. Baiker, Appl. Catal., A, 1997, $162,249$.

53 S. M. Auer, S. V. Gredig, R. A. Köppel and A. Baiker, J. Mol. Catal. A: Chem., 1999, 141, 193.

54 O. Jacquet, X. Frogneux, C. Das Neves Gomes and T. Cantat, Chem. Sci., 2013, 4, 2127.

55 A. Rit, T. P. Spaniol, L. Maron and J. Okuda, Angew. Chem., Int. Ed., 2013, 52, 4664.

56 (a) S. Das, D. Addis, K. Junge and M. Beller, Chem. - Eur. J., 2011, 17, 12186; (b) S. Das, D. Addis, S. Zhou, K. Junge and M. Beller, J. Am. Chem. Soc., 2010, 132, 1770.

57 Y. Li, X. Fang, K. Junge and M. Beller, Angew. Chem., Int. Ed., 2013, 52, 9568.

58 (a) Y. Li, I. Sorribes, T. Yan, K. Junge and M. Beller, Angew. Chem., Int. Ed., 2013, 52, 12156; (b) K. Beydoun, T. vom Stein, J. Klankermayer and W. Leitner, Angew. Chem., Int. Ed., 2013, 52, 9554.

59 (a) S. Wesselbaum, T. vom Stein, J. Klankermayer and W. Leitner, Angew. Chem., Int. Ed., 2012, 51, 7499; (b) J. Coetzee, D. L. Dodds, J. Klankermayer, S. Brosinski, W. Leitner, A. M. Z. Slawin and D. J. Cole-Hamilton, Chem. - Eur. J., 2013, 19, 11039; (c) A. A. Nunez Magro, G. R. Eastham and D. J. Cole-Hamilton, Chem. Commun., 2007, 3154; (d) F. M. A. Geilen, B. Engendahl, A. Harwardt, W. Marquardt, J. Klankermayer and W. Leitner, Angew. Chem. Int., Ed., 2010, 49, 5510; (e) F. M. A. Geilen, B. Engendahl, M. Holscher, J. Klankermayer and W. Leitner, J. Am. Chem. Soc., 2011, 133, 14349.

60 X. J. Cui, X. C. Dai, Y. Zhang, Y. Q. Deng and F. Shi, Chem. Sci., 2014, 5, 649. 